\title{
Laser in Battery Manufacturing - Impact of Intrinsic and Artificial Electrode Porosity on Chemical Degradation and Battery Lifetime
}

\author{
P. Smyrek ${ }^{* a, b}$, Y. Zheng ${ }^{\mathrm{a}}$, H.J. Seifert ${ }^{\mathrm{a}}$, W. Pfleging ${ }^{\mathrm{a}, \mathrm{b}}$ \\ ${ }^{a}$ Karlsruhe Institute of Technology, IAM-AWP, P.O. Box 3640, 76021 Karlsruhe, Germany \\ ${ }^{b}$ Karlsruhe Nano Micro Facility, H.-von-Helmholtz-Platz 1, 76344 Egg.-Leopoldshafen, Germany
}

\begin{abstract}
The main goal is to develop an optimized three-dimensional (3D) cell design with improved electrochemical properties, which can be correlated to a characteristic lithium distribution along 3D micro-structures at different State-of-Health $(\mathrm{SoH})$. 3D elemental mapping was applied for characterizing the whole electrode as function of SoH. It was demonstrated that fs-laser generated 3D architectures improves the battery performance regarding battery power and lifetime. It was quantitatively shown by laser-induced breakdown spectroscopy that $3 \mathrm{D}$ architectures act as attractor for lithium-ions. Furthermore, lateral intrinsic porosity variations were identified to be possible starting points for lithium plating and subsequent cell degradation. Results achieved from post-mortem studies of cells with laser structured electrodes (intrinsic and artificial porosity variation), and unstructured lithium-nickel-manganese-cobalt-oxide electrodes will be presented.
\end{abstract}

Keywords: Laser-induced breakdown spectroscopy, porosity, ultrafast laser structuring, lithium-ion battery, lithium nickel manganese cobalt oxide, cathode.

\section{INTRODUCTION}

Current research focuses on enhancement of energy and power densities as well as on cost-efficient production of lithium-ion batteries to fulfill the capability of powering hybrid and electric vehicles for long distances [1-4]. One innovative approach hereby is the merger of two battery design concepts: (i) the "thick film concept", which provides high energy densities due to a reduced amount of inactive materials [5] and (ii) the "three-dimensional (3D) battery concept", which enables high power applications due to an improved lithium-ion interfacial kinetic [6]. Certainly, both concepts base on an optimized 3D architecture with a defined porosity and a balanced 3D electrode topography on submicron and micrometer-scale, respectively.

In general, state-of-the-art lithium-ion batteries (LIBs) uses two-dimensional (2D) electrode designs (planar arrangements) with a film thickness of $50-60 \mu \mathrm{m}$. Due to limitations of achievable film thicknesses, 2D LIBs often require rather large areal footprints for delivering acceptable capacity and energy density. Another limiting factor that can become dominant is the current density distribution, depending on the relative distance from the reference electrode, which may lead to power losses at high charging and discharging currents [7]. One promising approach for overcoming the "2D" design challenges is the development of advanced lithium-ion electrode designs (3D battery concept), e.g., modified surface structures, which will promote high surface area, high rate capability, high cycle life-time, and less time-and-cost consuming electrolyte filling [7-10]. The general strategy in a 3D battery concept is to design cell architectures, which can maximize power and energy density yet maintain short ion transport distances. A 3D matrix of electrodes is proposed in order to meet short transport lengths and large energy capacity [11].

For evaluation of the new battery concept regarding application and further optimization of processing steps it is essential to correlate the 3D architectures (porosity, aspect ratio, topography, active surface area) with electrochemical performances and chemical data. Particularly the precise control of electrode porosity - which can vary on micro- and nanometer scale - has a great impact on battery life-time [12]. Liquid electrolyte has to penetrate into the entire porous electrode material and lithium-ion diffusion has to be enabled. Finally, the strength of embossing during calendering is a critical task, which finally has an impact on electrochemical performance with respect to lithium-ion migration, electrical conductivity, particle density and coating adhesion, respectively [13, 14]. The investigation of chemical data can be achieved by quantitative elemental mapping of the entire $3 \mathrm{D}$ electrode by using laser-induced breakdown spectroscopy 
(LIBS). For this type of application, LIBS is a rather new approach in order to achieve post-mortem information about chemical degradation of electrodes, from the surface down to the current collector interface. This analytic tool has a great potential to enable advanced fundamental studies on 3D electrode architectures for discovering their impact on performance enhancement regarding life-time and capacity under abuse conditions and as a function of electrochemical cycling parameters $[15,16]$.

\section{EXPERIMENTAL}

\subsection{Adjustment of Porosity Variations in $\mathrm{Li}\left(\mathrm{Ni}_{1 / 3} \mathrm{Mn}_{1 / 3} \mathrm{Co}_{1 / 3}\right) \mathrm{O}_{2}$ Thick Films}

The manufacturing procedure of lithium nickel manganese cobalt oxide $\left(\mathrm{Li}(\mathrm{NiMnCo}) \mathrm{O}_{2}(\mathrm{NMC}), \mathrm{Ni}: \mathrm{Mn}: \mathrm{Co}=1: 1: 1\right)$ cathodes used in this work is described elsewhere [15]. For investigating the impact on porosity variations within the electrodes, two different methods were used for the generation of three-dimensional (3D) architectures (Figure 1). Figure 1(a) shows a schematic diagram of a femtosecond laser structured NMC thick film, which offers micro-capillary structures with a channel width of $600 \mu \mathrm{m}$. The micro-capillary structures were generated by removing the composite material down to the current collector. By using ultrafast laser radiation, an artificial porosity could be generated between each micro-structure. During processing, the 3D micro-capillary structures were generated by using a micromachining laser workstation (PS450TO, Optec s.a., Belgium) equipped with an ultrafast fiber laser (Tangerine, Amplitude Systèmes, France). The process was performed under ambient air by using a pulse duration of 380 femtoseconds (fs). Furthermore, a wavelength of $515 \mathrm{~nm}$ and a repetition rate of $500 \mathrm{kHz}$ were applied. The laser beam was guided through a beam expander (3-fold) and an average power of $1.45 \mathrm{~W}$ was measured at the electrode surface. In comparison to laser ablation, figure 1(b) demonstrates the processing steps of compression molding, which can be also used for generation of 3D micro-structures within the electrode. Here, an embossing tool was impressed into the material until a defined film thickness $(100 \mu \mathrm{m})$ was reached. After relaxation, the $3 \mathrm{D}$ electrodes offer porosities in the range of $34 \%-55 \%$.

(a)
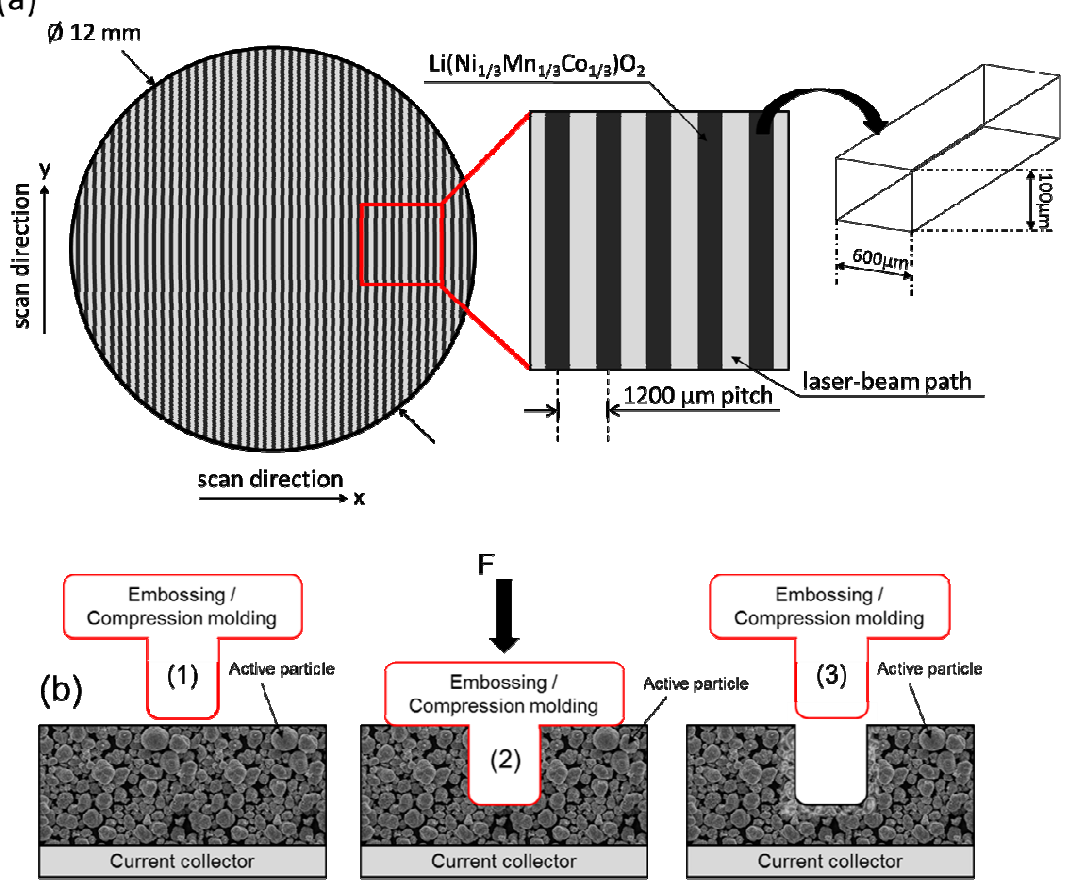

Figure 1: Schematic diagram of processing steps for the generation of 3D micro-structures: (a) fs-laser structuring of NMC thick film electrodes and (b) generation of 3D architectures by embossing. 


\subsection{Electrochemical Characterization of Three-Dimensional NMC Electrodes}

For battery testing, NMC electrodes were cut by fs-laser into circular disks with $12 \mathrm{~mm}$ in diameter. Subsequently, all cathodes were heated in a vacuum oven (VT 6025, Thermo SCIENTIFIC, Germany) at $130{ }^{\circ} \mathrm{C}$ for $24 \mathrm{~h}$. Additionally, the cells were assembled in an argon-filled glove box (LABmaster sp, M. Braun Inertgas-Systeme $\mathrm{GmbH}_{2} \mathrm{H}_{2} \mathrm{O}<0.1 \mathrm{ppm}$ and $\mathrm{O}_{2}$ $<0.1 \mathrm{ppm}$ ) using the Swagelok ${ }^{\circledR}$ cell design. The principle set-up of the electrochemical cell is described elsewhere [16]. Galvanostatic measurements of NMC electrodes with porosity variations in the range of $34 \%-55 \%$ were performed by using a BT2000 battery cycler (Arbin Instruments, USA). In a first approach, a formation step were performed for both types of electrodes (laser structured and embossed). The C-rates for charging and discharging were set to C/10, which correlates to 10 hours for charging and discharging. Totally, three cycles were applied. In a second approach, the cells were further electrochemically cycled at $\mathrm{C}$-rates in the range of $\mathrm{C} / 2$ and $2 \mathrm{C}$ (table 1). After electrochemical testing, the cells were disassembled, washed in DMC (two times 30 minutes in fresh DMC) and finally investigated by LIBS.

Table 1: Electrochemical testing procedure for Swagelok ${ }^{\circledR}$ cells with laser structured and embossed NMC thick film electrodes.

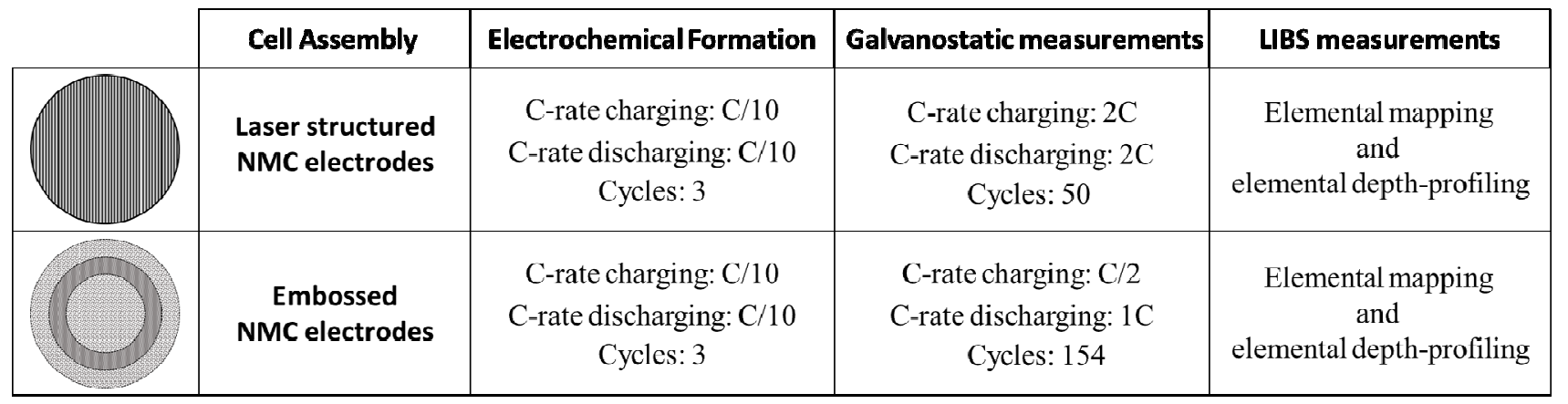

\subsection{Laser-Induced Breakdown Spectroscopy (LIBS)}

The experimental setup of LIBS (SN013, Secopta Analytics GmbH, Germany) used in this study is described elsewhere [15]. Briefly, a pulsed passive mode-locked diode pumped solid state Nd:YAG laser was used for the generation of a laser-induced plasma at the sample surface. The nanosecond laser operates at a wavelength of $1064 \mathrm{~nm}$ with a maximum pulse energy of $3 \mathrm{~mJ}$. The repetition rate can be varied in the range of $1 \mathrm{~Hz}$ up to $100 \mathrm{~Hz}$ and a laser power density of about $25 \mathrm{GW} / \mathrm{cm}^{2}$ could be finally achieved at the sample surface. Czerny-Turner spectrometer equipped with a ruled grating of 1200 grooves / $\mathrm{mm}$ blazed at $250 \mathrm{~nm}$ was coupled with a back-thinned charge-coupled detector (CCD) including an electronic shutter function (Hamamatsu S11155) in order to detect the dispersed light from the laser-induced plasma. The CCD had a pixel width of $14 \mu \mathrm{m}$ and covers spectral ranges of $229 \mathrm{~nm}-498 \mathrm{~nm}$ and $569 \mathrm{~nm}-792 \mathrm{~nm}$.

\section{RESULTS AND DISCUSSION}

\subsection{LIBS Investigation of Lithium Distribution in Laser Structured and Embossed NMC Thick Films}

For the characterization of lithium distribution on laser structured and embossed electrode surfaces, LIBS was applied post-mortem (after battery tests). As depicted in figure 2 and 3, two different methods were used for the generation of 3D micro-structures, laser structuring and embossing. Figure 2(a) shows an electrode design, which was manufactured by fslaser radiation. Micro-capillary structures were formed with a channel width of $600 \mu \mathrm{m}$. The thickness of each fs-laser structured electrode was measured to $100 \mu \mathrm{m}$ and a porosity of $34 \%$ could be calculated. Additionally, the pitch distance was set to $1200 \mu \mathrm{m}$. In comparison to laser ablation, an alternative classic "non-laser structuring technology was applied (figure 3(a)). Embossing was carried out for the formation of different geometrical patterns on the electrode. Finally, porosity patterns could be realized containing low- and high porosity regions with porosity values of $34 \%$ and $55 \%$, respectively. 
(a)

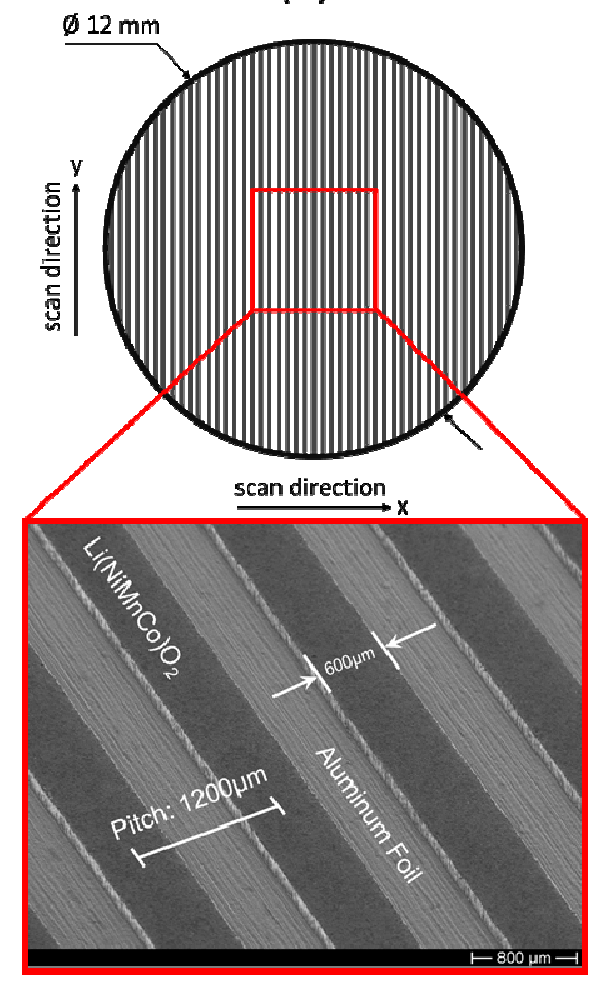

(b)

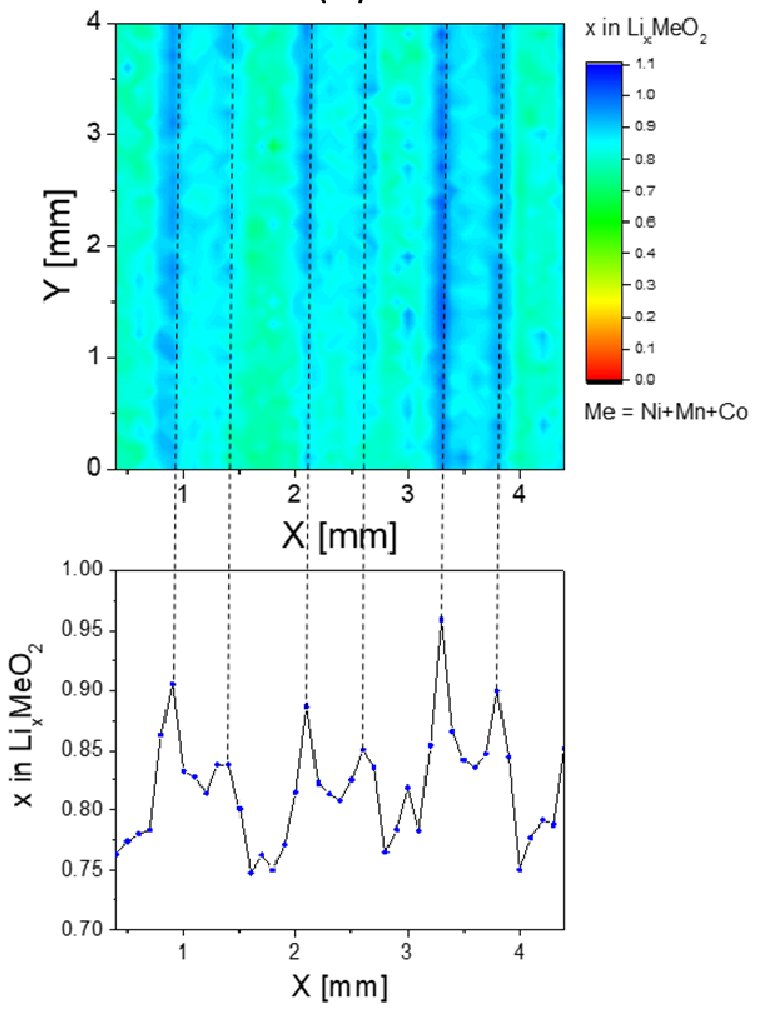

Figure 2: Ultrafast laser structuring of $\mathrm{Li}\left(\mathrm{Ni}_{1 / 3} \mathrm{Mn}_{1 / 3} \mathrm{Co}_{1 / 3}\right) \mathrm{O}_{2}$ thick film electrodes: (a) schematic diagram and SEM image (top-view) of an NMC cathode with micro-cappillary structures (width: $600 \mu \mathrm{m}$, height: $100 \mu \mathrm{m}$ ), and (b) LIBS elemental mapping (lithium) of a fs-laser structured NMC thick film. LIBS was performed after electrochemical cycling (3 cycles at C/10 $\mathrm{C} / 10,50$ cycles at $2 \mathrm{C}-2 \mathrm{C})$. The elemental mappings represent the lithium concentration $\mathrm{x}$ in $\mathrm{Li}_{\mathrm{x}}\left(\mathrm{Ni}_{1 / 3} \mathrm{Mn}_{1 / 3} \mathrm{Co}_{1 / 3}\right) \mathrm{O}_{2}$.

For post-mortem identification of chemical inhomogeneities, LIBS measurements were applied with a lateral resolution of $100 \mu \mathrm{m}$. Both types of electrodes were completetly screened layer-by-layer using a measurement area of $13 \mathrm{~mm} \times 13$ $\mathrm{mm}$ covering the entire electrode surface. The pitch distance of each laser pulse was set to $100 \mu \mathrm{m}$, which corresponds to $131 \times 131=17131$ measurement locations. The lithium distribution was investigated as function of State-of-Health (table 1). For both types of electrodes, the $3^{\text {rd }}$ layer was selected for the following discussion.

In a first approach, laser structured electrodes with a homogeneous porosity of $34 \%$ were investigated post-mortem by LIBS. For this purpose, the electrochemical cell test was stopped after 50 cycles. The cell was disassembled and analyzed by LIBS in order to determine the lithium distribution at high power conditions (C-rate for charging / discharging $=2 \mathrm{C} / 2 \mathrm{C}$ ). Along $\mathrm{y}$-direction (see figure $2(\mathrm{~b})$ ) the averaged lithium concentration $\mathrm{x}$ was calculated and plotted as function of $\mathrm{x}$-direction. This value covers a range from $\mathrm{x}=0.75$ up to 0.96 . The lithium concentration is significantly increased along the contour of the laser generated line structure, indicating an increase of lithium mobility during battery operation at high power conditions. The local change of Li concentration $\mathrm{x}$ clearly indicates that fs-laser generated micro-capillary structures provide new Li-diffusion pathways along the structure sidewalls, i,e, the microstructures act as an attractor for lithium-ions at high C-rates. Finally, a boost in battery performance regarding battery power could be obtained. Furthermore, the artificial porosity induced by fs-laser ablation act as electrolyte reservoir during electrochemical cycling and has a positive impact on cell life-time. 
(a)

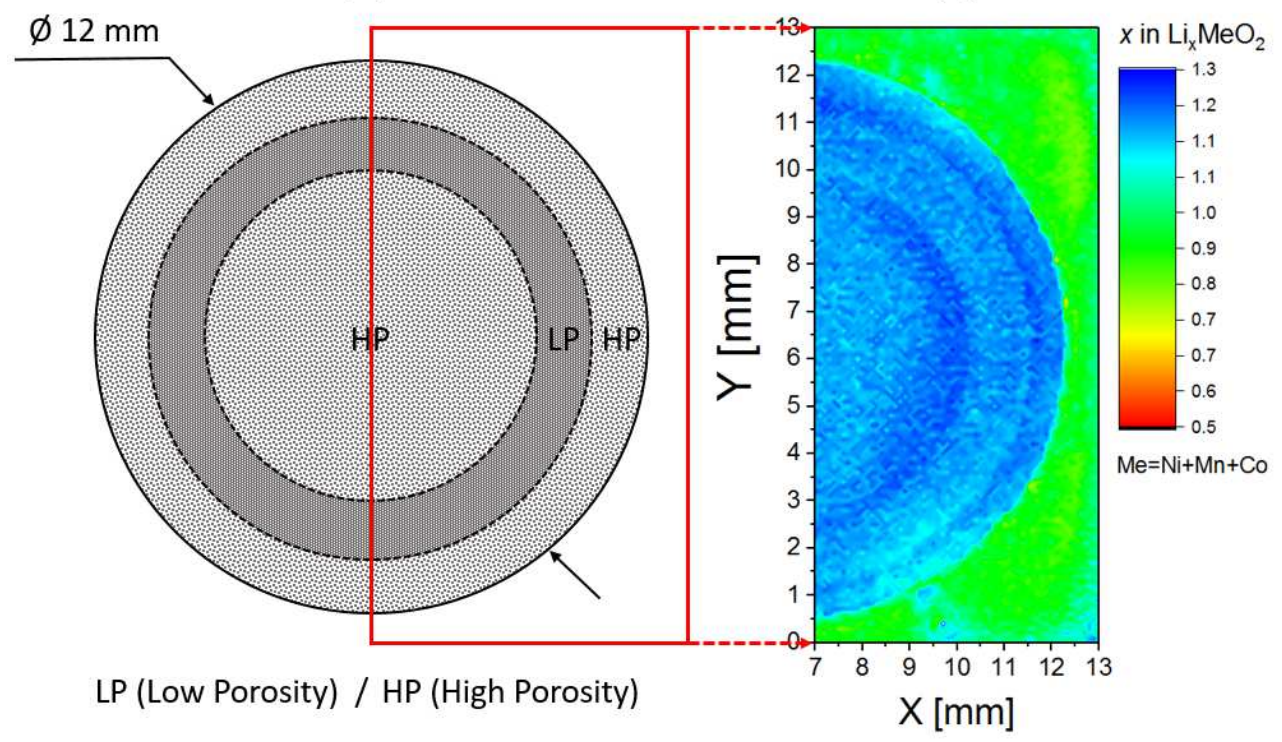

Figure 3: Generation of porosity pattern by embossing: (a) schematic diagram of embossed $\mathrm{Li}\left(\mathrm{Ni}_{1 / 3} \mathrm{Mn}_{1 / 3} \mathrm{Co}_{1 / 3}\right) \mathrm{O}_{2}$ thick film electrode with different type of porosity, LP $34 \%$ and HP $55 \%$, and (b) post mortem LIBS elemental mapping (lithium) of an embossed NMC thick film electrode. The lithium distribution was measured after electrochemical cycling ( 3 cycles at C/10 $\mathrm{C} / 10,154$ cycles at $\mathrm{C} / 2-1 \mathrm{C})$. The elemental mappings represent the lithium distribution $\mathrm{x}$ in $\mathrm{Li}_{\mathrm{x}}\left(\mathrm{Ni}_{1 / 3} \mathrm{Mn}_{1 / 3} \mathrm{Co}_{1 / 3}\right) \mathrm{O}_{2}$.

In a second approach, an embossed NMC electrode was characterized post-mortem by LIBS in order to identify chemical inhomogeneities on electrode surfaces with varying porosities. After cycle number 154 (table 1) a spontaneous cell failure could be observed. The electrode screening by LIBS clearly indicates a change in lithium distribution for lowand high porosity regions. Porosity variations lead to different lithium mobilities and electrical currents, which in turn will force the chemically driven aging process during battery operation. A well-defined porosity is quite crucial for electrochemical cyclability [12,13], especially for NMC thick films operating at high charging and discharging currents. Furthermore, the cell failure was obviously induced by local lithium plating which could be detected postmortem in an area between low and high porosity (not shown here).

\section{CONCLUSIONS}

In this work, the impact of intrinsic and laser generated artificial electrode porosity on chemical degradation and battery lifetime was reported. For detecting an optimized 3D electrode architecture, laser-induced breakdown spectroscopy (LIBS) was introduced as a powerful analytical item and was applied post-mortem (after battery tests) for quantitative characterization of laser generated and classical structured (embossed) thick film electrodes. Elemental mapping and elemental depth-profiling were established in order to enable a rapid screening of the chemical composition of the entire 3D electrodes (surface and bulk), which in turn provides a rapid feedback control between electrochemical performance and 3D microstructures. Mechanical structuring such as embossing was studied as an alternative non-laser structuring technology. It could be clearly demonstrated that embossing leads to an inhomogeneity in material density, which in turn has an impact on the porosity distribution. It was shown by LIBS that for embossed electrode surfaces with an intrinsic porosity variation a local change in lithium distribution is obtained. This is due to a change in lithium mobility as function of electrode porosity. A change in lithium mobility results in a dramatic chemically-driven aging process during battery operation. In comparison to embossing, the innovative fs-laser patterning technology provides an artificial porosity which was proven to have a positive impact on battery performance and battery life-time. It was shown that the lithium distribution significantly increased along the contour of each micro-capillary structure, especially at high charging / discharging currents. New diffusion pathways were generated which becomes activated for high battery power operation. 


\section{ACKNOWLEDGMENT}

We are grateful to our colleagues H. Besser and J. Anhalt for their technical assistance during laser material processing and LIBS. This project has received funding from the European Union's Horizon 2020 research and innovation programme under the Marie Sklodowska-Curie grant agreement no. 644971. Finally, the support for laser materials processing by the Karlsruhe Nano Micro Facility (KNMF, http://www.knmf.kit.edu/) a Helmholtz research infrastructure at the Karlsruhe Institute of Technology (KIT) is gratefully acknowledged.

\section{REFERENCES}

[1] An, S.J., Li, J., Du, Z., Daniel, C. and Wood III, D.L., "Fast formation cycling for lithium ion batteries," J. Power Sources 342, 846-852 (2017).

[2] De Hoog, J., Timmermans, J.-M., Ioan-Stroe, D., Swierczynski, M., Jaguemont, J., Goutam, S., Omar, N., Van Mierlo, J. and Van Den Bossche, P., "Combined cycling and calendar capacity fade modeling of a NickelManganese-Cobalt Oxide Cell with real-life profile validation," Appl. Energy 200, 47-61 (2017).

[3] Leng, F., Wei, Z., Ming Tan, C. and Yazami, R., "Hierarchical degradation processes in lithium-ion batteries during ageing," Electrochim. Acta 256, 52-62 (2017).

[4] Chen, C.-F., Barai, P., Smith, K. and Mukherjee, P.P., "Scaling Relations for Intercalation Induced Damage in Electrodes," Electrochim. Acta 204, 31-49 (2016).

[5] Singh, M., Kaiser, J. and Hahn, H., "A systematic study of thick electrodes for high energy lithium ion batteries," J. Electroanal. Chem. 782, 245-249 (2016).

[6] Xie J., Oudenhoven, J. F. M., Li, D., Chen, C., Eichel, R.-A. and Notten, P. H. L., "High Power and High Capacity 3D-Structured $\mathrm{TiO}_{2}$ Electrodes for Lithium-Ion Microbatteries," J. Electrochem. Soc. 163, A2385A2389 (2016).

[7] Ferrari, S., Loveridge, M., Beattie, S. D., Jahn, M., Dashwood, R. J. and Bhagat, R., "Latest advances in the manufacturing of 3D rechargeable lithium microbatteries," J. Power Sources 286, 25-46 (2015).

[8] Xia, H., Wan, Y., Assenmacher, W., Mader, W., Yuan, G. and Lu, L., "Facile synthesis of chain-like $\mathrm{LiCoO}_{2}$ nanowire arrays as three-dimensional cathode for microbatteries," NPG Asia Mater. 6, 1-6 (2014).

[9] Xiong, W., Xia, Q. and Xia, H., "Three-dimensional self-supported metal oxides as cathodes for microbatteries," Functional Materials Letters 7, 1430003-1 - 1430003-10 (2014).

[10] Pfleging, W. and Pröll, J., "A new approach for rapid electrolyte wetting in tape cast electrodes for lithium-ion batteries," J. Mater. Chem. A 2, 14918-14926 (2014).

[11] Long, J. W., Dunn, B., Rolison, D. R. and White, H. S., “Three-Dimensional Battery Architectures,” Chem. Rev. 104, 4463-4492 (2004).

[12] Meyer, C., Bockholt, H., Haselrieder, W. and Kwade, A. "Characterization of the calendering process for compaction of electrodes for lithium-ion batteries," J. Mater. Process. Technol. 249, 172-178 (2017).

[13] Zheng, H., Tan, L., Liu, G., Song, X. Y. and Battaglia, V. S., "Calendering effects on the physical and electrochemical properties of $\mathrm{Li}\left[\mathrm{Ni}_{1 / 3} \mathrm{Mn}_{1 / 3} \mathrm{Co}_{1 / 3}\right] \mathrm{O}_{2}$ cathode," J. Power Sources 208, $52-57$ (2012).

[14] Zheng, H., Liu, G., Song, X., Ridgway, P., Xun, S. and Battaglia, V. S., "Cathode Performance as a Function of Inactive Material and Void Fractions,” J. Electrochem. Soc. 157 (10), A1060-A1066 (2010). 
[15] Smyrek, P., Pröll, J., Seifert, H.J. and Pfleging, W., "Laser-Induced Breakdown Spectroscopy of Laser-Structured $\mathrm{Li}(\mathrm{NiMnCo}) \mathrm{O}_{2}$ Electrodes for Lithium-Ion Batteries," J. Electrochem. Soc. 163, A19-A26 (2015).

[16] Smyrek, P., Zheng, Y., Rakebrandt, J.-H., Seifert, H. J. and Pfleging, W., "Investigation of Micro-Structured $\mathrm{Li}\left(\mathrm{Ni}_{1 / 3} \mathrm{Mn}_{1 / 3} \mathrm{Co}_{1 / 3}\right) \mathrm{O}_{2}$ Cathodes by Laser-Induced Breakdown Spectroscopy," Proc. of SPIE Vol. 10092, 100920S-1 - 100920S-7 (2017). 